\title{
Medievalista
}

Online

$25 \mid 2019$

Número 25

\section{Carmen Benítez Guerrero, Crónica de Fernando IV. Estudio y edición de un texto postalfonsí}

\section{Filipe Alves Moreira}

\section{(2) OpenEdition}

1 Journals

\section{Edição electrónica}

URL: http://journals.openedition.org/medievalista/1754

DOI: 10.4000/medievalista.1754

ISSN: 1646-740X

\section{Editora}

Instituto de Estudos Medievais - FCSH-UNL

\section{Refêrencia eletrónica}

Filipe Alves Moreira, « Carmen Benítez Guerrero, Crónica de Fernando IV. Estudio y edición de un texto postalfonsí », Medievalista [Online], 25 | 2019, posto online no dia 17 março 2019, consultado o 23 setembro 2020. URL : http://journals.openedition.org/medievalista/1754 ; DOI : https://doi.org/ 10.4000/medievalista.1754

Este documento foi criado de forma automática no dia 23 setembro 2020.

Mediavalista está licenciado com uma Licença Creative Commons - Atribuição-NãoComercial 4.0 Internacional. 


\title{
Carmen Benítez Guerrero, Crónica de Fernando IV. Estudio y edición de un texto postalfonsí
}

\author{
Filipe Alves Moreira
}

\section{REFERÊNCIA}

BENÍTEZ GUERRERO, Carmen - Crónica de Fernando IV. Estudio y edición de un texto postalfonsí. Sevilha: Editorial Universidad de Sevilla y Cátedra Alfonso X El Sabio, 2017 (217 pp.)

\section{NOTA DO EDITOR}

Data recepção do artigo / Received for publication: 01-09-2018

1 Contrariamente ao que sucede com as crónicas medievais portuguesas, as crónicas castelhanas têm sido alvo de uma atenção constante e dedicada por parte de uma comunidade de investigadores relativamente alargada, para além de coesa e atenta. Em resultado de tudo isto, têm surgido, nos últimos anos, diversos e importantes estudos, colóquios e teses. Também várias edições têm sido produzidas, disponibilizando-se desta forma um conjunto de textos que permaneciam inéditos ou muito insuficientemente editados. Disto mesmo é exemplo esta edição da Crónica de Fernando IV (rei entre 1295 e 1312; a crónica datará de ca. 1340), da responsabilidade de uma das melhores e mais promissoras estudiosas destes assuntos, Carmen Benítez Guerrero, da Universidade de Sevilha.

2 A edição aqui em apreço resulta da adaptação da Tese de Doutoramento da autora, apresentada à Universidade de Sevilha em 2015, e defendida em fevereiro de 2016. Por razões técnicas (e eventualmente orçamentais), optou-se por apresentar um volume impresso, com a edição da crónica e um longo e denso estudo introdutório (162 
páginas), juntamente com um Cd-rom que inclui uma versão mais extensa (porque com um aparato de variantes mais detalhado) desta mesma edição, e um conjunto de quadros e informações várias sobre os manuscritos utilizados. É uma opção perfeitamente lógica, viável e compreensível, muito embora nos possamos interrogar sobre o eventual aumento do custo do volume que ela implica, assim como serão legítimas algumas dúvidas sobre a plausivelmente rápida caducidade do suporte $\mathrm{Cd}$ rom, em época de aceleradíssima evolução tecnológica. O ideal seria, talvez, a disponibilização online de todos estes materiais.

3 Estamos perante uma edição notável. $\mathrm{O}$ aspeto gráfico e físico do volume é cómodo e atraente, e o trabalho editorial é rigorosíssimo e revela uma aguda consciência de teorias e metodologias de crítica textual, facto tanto mais de salientar quanto a autora tem uma formação académica de base como historiadora, o que poderia afastá-la de certos aspetos mais técnicos destas questões. Além disso, a bibliografia utilizada é vasta e inclui quer estudos clássicos, quer estudos muito recentes (é referida, por exemplo, uma Tese de Doutoramento defendida em 2016). A única exceção a esta acribia bibliográfica parecem-me ser os momentos, aliás compreensivelmente breves, em que a autora se refere às crónicas afonsinas e pós-afonsinas (finais do séc. XIII e inícios do XIV): de forma algo incompreensível, a bibliografia citada a este propósito raramente ultrapassa o ano 2000 (veja-se, p. ex., as pp. XXVII e XXVIII da Introdução) e a visão global que daí resulta afigura-se-me o seu tanto simplista. Outra razão para que estejamos, globalmente, perante uma edição notável é o estilo argumentativo e de escrita da autora: claro e preciso, sem deixar de ser denso, mas também enérgico e corajoso. Carmen Benítez tem ideias próprias, e não receia dizer, com frontalidade, que não adere a esta ou àquela tese, muito embora o faça de modo bastante elegante. Sobre tudo isto, são raríssimas as (sempre inevitáveis) gralhas de monta: um dos escassos casos que verifiquei ocorre na nota de rodapé número 254, que remete, erroneamente, para a nota 215 , deixando o leitor um pouco confuso. Vejamos resumidamente, e com alguns ligeiros comentários, a estrutura e os conteúdos desta edição.

4 Antes da Introdução propriamente dita, surge uma "Nota preliminar" (pp. XVII-XX), porventura excessivamente longa, mas em que se dão conta dos objetivos globais pretendidos: dado o elevado número de manuscritos existentes da Crónica de Fernando IV (mais de 40), a autora não apresenta uma edição que tenha em conta todas as variantes de todos os manuscritos, mas também não se limita a apresentar o texto de um deles; a meio caminho entre ambas estas posições, do que aqui se cuida é de "seleccionar un primer grupo de testimonios con los que trabajar para avanzar en el análisis de la historia textual, y ofrecer una nueva edición, aunque sólo fuera provisional desde un punto de vista crítico, al menos desde una perspectiva neolachmaniana" (p. XVIII). Em consonância com este programa tipicamente 'ao centro' (permita-se-me a metáfora política), a autora declara ainda fazer-se eco do elogio da variante (alusão a uma obra polémica e discutível de finais dos anos 1980) e da mouvance (conceito zumthoriano), sem renunciar à noção de autor e de texto original. Por tudo isto, prefere a autora "no emplear el apelativo de crítica en el título del trabajo" (p. XIX). Se, porém, considerarmos como 'edição crítica' uma que resulte de um processo teórica e metodologicamente conduzido de distanciamento em relação ao objeto / texto, o que aqui temos é uma edição deveras crítica.

5 O estudo introdutório divide-se em quatro grandes secções: "Presupuestos prévios" [e haverá pressupostos não prévios?], "La Crónica de Fernando IV: textualidad y 
contextualidad", "La transmisión manuscrita de la Crónica de Fernando IV" e "Conclusiones". Ou seja: uma vez explicitados os critérios e metodologias de base, a exposição vai seguindo uma ordenação basicamente cronológica, desde o momento de feitura da versão original da crónica, até às cópias sucessivamente feitas e ao trabalho editorial que com base nelas se propõe. A elucidação dos pressupostos básicos desenvolve o programa 'ao centro' resumido na nota prévia, e fá-lo, como é costume na autora, de forma clara e precisa. É especialmente enérgica e interessante a defesa, aí feita, da edição do texto medieval como terra de fronteira entre a Filologia e a História (p. XXVI).

6 O estudo da autoria, contexto e condições de produção da Crónica de Fernando IV é uma das mais interessantes partes do estudo introdutório. Carmen Benítez expõe com firme convicção a debilidade de alguns argumentos que têm sido avançados para sustentar que o autor desta crónica (e das de Afonso X e Sancho IV, que com ela formarão o conjunto conhecido por Crónica de tres reyes) foi Fernán Sánchez de Valladolid (ca. 1290 - ca. 1364), chanceler do rei Afonso XI (r. 1312 - 1350), considerando que a única possibilidade criticamente sustentável é desenhar:

un perfil para el autor de la Crónica de tres reyes o al menos para la persona que da forma final al texto, selecciona las fuentes y vela - con más o menos éxito - porque todo él responda a un mensaje unitário (p. XXXII).

7 Nesse perfil (que seria o de alguém do entorno do rei Afonso XI, com fácil acesso a materiais da câmara real e conhecimentos jurídicos) cabe, no entanto, perfeitissimamente bem a figura de Sánchez de Valladolid... Carmen Benítez retoma e aprofunda, ainda, uma velha ideia, segundo a qual a Crónica de Fernando IV seria especialmente devedora de materiais prévios redigidos por Nuño Pérez de Monroy, abade de Santander, morto em 1326. A este propósito, parece-me, porém, haver certa indefinição de conceitos, pois a autora menciona por diversas vezes o que chama de "processo de composición que conoce distintas fases" (p. XXXVII), confundindo, por vezes, a meu ver, isso com o aproveitamento de materiais de distintas caraterísticas e origens; também o conceito de autor aqui considerado dará pé a algumas confusões, como se vê da citação atrás deixada: neste contexto, que é, afinal, um autor, senão alguém que "da forma final al texto, seleciona las fuentes y vela [...] porque todo él responda a un mensaje unitário"?

8 É em seguida abordado o problema da consideração da Crónica de Fernando IV como uma obra autónoma, ou como parte de um conjunto, a Crónica de tres reyes. Carmen Benítez defende perspicazmente a segunda opção, o que a leva a minimizar (bem, segundo creio) a importância das, reais ou supostas, divergências de método e conceções notadas entre esta Crónica e as de Afonso X e Sancho IV. Será especialmente pertinente, neste ponto, a ideia de Diego Catalán (que Benítez cita, na p. LXIII, a outro propósito), segundo a qual "en la Historiografia medieval, los textos formal, estructural e ideologicamente mixtos son más comunes que los que responden a unos princípios unitários". Em todo o caso, e como frequentemente sucede, Carmen Benítez termina este apartado alertando para a provisoriedade das suas conclusões e a necessidade de as aprofundar.

9 A discussão do contexto ideológico de produção da Crónica conduz Carmen Benítez a entrar na polémica questão do molinismo, isto é, a existência, ou não, de um modelo político e cultural, com caraterísticas próprias (descritas nas pp. LX e LXI), impulsionado pela corte régia (e especialmente pelo entorno próximo da rainha María 
de Molina, mulher de Sancho IV, mãe de Fernando IV e avó de Afonso XI) e com o qual estaria ainda relacionada, de algum modo, a feitura da Crónica de tres reyes. Com isto se relaciona a problemática da existência, ou não, de focos de produção historiográfica alheios à corte régia castelhana por estas épocas, bem como a das relações entre monarquia e aristocracia. Começando por expor as visões, antagónicas entre si, de estudiosos como Fernando Gómez Redondo e Leonardo Funes, Carmen Benítez acaba por adotar uma posição próxima das de outros estudiosos, como Manuel Hijano Villegas: posta em causa a pertinência e a extensão do conceito de molinismo, não se segue daqui a necessidade de excluir da órbita da corte régia a produção historiográfica da época hoje distinguida; produção historiográfica de origem nobiliárquica terá existido, sim, mas o que hoje conhecemos resultará, basicamente, de reformulações e aproveitamentos feitos no âmbito da corte régia. 0 mais importante de tudo isto será, porém, a forma como Carmen Benítez chama a atenção para a necessidade de se reverem postulados teóricos que exacerbam, de forma excessiva e algo pré-concebida, a oposição monarquia/aristocracia, erigindo-a, mesmo, a critério último de legibilidade histórica, esquecendo ou minimizando o papel de outros agentes histórico-culturais. Perfeitamente de acordo com esta visão da autora, diria apenas que me parece excessiva a ideia, exposta na p. LVI, de que a adoção deste modelo interpretativo resulta de "contagio de la estructura hace años propuesta por Luis Suárez Fernández para el siglo XV", pois outras influências, designadamente a historiografia francesa dos anos 60-70 (ou certas leituras dela), me parecem igualmente responsáveis pelo quadro analítico traçado.

Sobre a tradição manuscrita da Crónica de Fernando IV, Carmen Benítez começa por traçar uma rápida, porque reduzida ao essencial, revisão das edições existentes (bastante más pelos critérios atuais) e dos (escassos) trabalhos que se têm ocupado dos manuscritos desta Crónica, com destaque para os de Marcelo Rosende, e também de estudiosos que têm trabalhado com a tradição manuscrita das Crónicas de Afonso X (Paula K. Rodgers), Sancho IV (Pablo Saracino) e Afonso XI (Diego Catalán), os quais importa ter em conta pelo facto de vários manuscritos conterem uma, ou mais, destas crónicas. Segue-se um elenco dos manuscritos conhecidos, alguns deles identificados, pela primeira vez, pela autora, e análises densíssimas do seu conteúdo, das relações entre eles estabelecidas (incluindo uma proposta de stemma que abrange alguns deles, os que se têm em conta nesta edição) e de alguns loci critici, por exemplo o controvertido problema da configuração original dos últimos capítulos da Crónica de Fernando IV (e dos iniciais da de Afonso XI).

11 Benítez é geralmente bastante convincente com os seus argumentos, mesmo reconhecendo a imensa complexidade destas questões, e poucas observações lhe poderei fazer. Parece-me, apenas, que seria desejável prestar um pouco mais de atenção à edição de 1554 (única existente anteriormente ao século XIX), e explicitar um pouco mais os critérios que levaram a autora a excluir da sua análise determinados manuscritos. Assim, por exemplo, justifica-se a omissão de certos manuscritos pelo grau de reelaboração que eles apresentam (p. LXXVI), mas um outro manuscrito é tido mais em conta, não obstante a autora reconhecer que ele patenteia, igualmente, um elevado grau de reformulação do texto (p. CVII). Sendo compreensível que, por razões várias, a autora adote o seu próprio sistema de siglas para designar a tradição manuscrita da Crónica de Fernando IV, seria, no entanto, extremamente cómodo que tivesse podido adotar o sistema de Saracino e de Rosende, já que isso ajudaria, certamente, os estudiosos do futuro a evitar certas confusões (o exemplo da Estoria de 
España e crónicas com ela relacionadas, cujos estudiosos foram mantendo o sistema de siglas previamente estabelecido é, a este respeito, modelar). Nos pontos em que Carmen Benítez discrepa de Rosende, os seus argumentos são geralmente convincentes, mas nem sempre. Parece-me, por exemplo, que Rosende tem razão em salientar o facto de que nada obrigava os cronistas a seguirem, na ordem de feitura das crónicas, a ordem cronológica dos sucessivos reinados - e Benítez, ao socorrer-se, neste ponto (p. CII), de exemplos como os da chamada Crónica de Fernando III como continuação da Estoria de España, ou da obra de Loaysa como continuação da obra de Rodrigo Jiménez de Rada está, em meu entender, a comparar o incomparável.

A forma como a autora analisa as relações existentes entre os manuscritos tidos em conta é minuciosa e revela um domínio perfeito de técnicas editoriais, ainda as mais exigentes. Como seria expectável tendo em vista o programa previamente exposto, Carmen Benítez dedica especial atenção a interpolações específicas de determinados manuscritos. Para os portugueses, e para os interessados nas crónicas e na História de Portugal, tem um interesse muito especial a inclusão, num desses manuscritos, de um episódio protagonizado pelo rei D. Dinis, cuja função parece ser, entre outras, a de explicar o surgimento do epíteto "D. Dinis, que fez [ou "fiz"] quanto quis". o episódio em questão não aparece em nenhum texto português conhecido, mas o epíteto comparece em Sumários de Crónicas portugueses do século XVI, como a autora refere (pp. CXXXIX-CXLI). Segue-se a edição propriamente dita, de acordo com os critérios previamente expostos, os quais são criteriosamente seguidos.

Em suma, o leitor interessado, ou simplesmente curioso, tem aqui uma excelente edição, sem dúvida a melhor existente da Crónica de Fernando IV. Mais do que isso, estamos perante um magnífico exemplo de verdadeira interdisciplinaridade aplicada, e ainda de uma boa porta de entrada para o complexíssimo universo das crónicas castelhanas do século XIV.

\section{AUTORES}

\section{FILIPE ALVES MOREIRA}

Centro de Literaturas e Culturas Lusófonas e Europeias, Faculdade de Letras, Universidade de Lisboa, 1600-214 Lisbon, Portugal

Instituto de Filosofia, Universidade do Porto, 4150-564 Porto, Portugal

gomeseanes@gmail.com

https://orcid.org/0000-0002-7426-7395 